\title{
Wegner, Bernd, Hitlers politische Soldaten : die Waffen-SS 1933-1945 - Leitbild, Struktur und Funktion einer nationalsozialistischen Elite
}

\section{Sébastien Bertrand}

\section{OpenEdition}

\section{Journals}

Édition électronique

URL : http://journals.openedition.org/ifha/2259

DOI : 10.4000/ifha.2259

ISSN : 2198-8943

Éditeur

IFRA - Institut franco-allemand (sciences historiques et sociales)

Référence électronique

Sébastien Bertrand, « Wegner, Bernd, Hitlers politische Soldaten : die Waffen-SS 1933-1945 - Leitbild, Struktur und Funktion einer nationalsozialistischen Elite », Revue de l'IFHA [En ligne], Date de recension, mis en ligne le 01 janvier 2010, consulté le 22 septembre 2020. URL : http://journals.openedition.org/ ifha/2259; DOl : https://doi.org/10.4000/ifha.2259

Ce document a été généré automatiquement le 22 septembre 2020.

(CIFHA 


\title{
Wegner, Bernd, Hitlers politische Soldaten : die Waffen-SS 1933-1945 - Leitbild, Struktur und Funktion einer nationalsozialistischen Elite
}

\author{
Sébastien Bertrand
}

1 Le renouvellement des études sur la Wehrmacht des vingt dernières années a logiquement amené à redécouvrir l'histoire des soldats politiques d'Hitler et à réexaminer le parcours de la Waffen-SS, maigre troupe de police auxiliaire au milieu des années trente devenue une armée multinationale de près de 900000 hommes à la fin de la guerre. C'est peut-être pour cela que les éditions Schöningh rééditent pour la huitième fois le livre de B.W., issu de travaux menés à l'Université de Hambourg et longtemps considéré comme le Standardwerk sur la Waffen-SS (comme le souligne le prologue de la cinquième édition en 1996).

2 Constatant dans les années soixante-dix que la plupart des ouvrages consacrés à la Waffen-SS pêchent par un parti pris idéologique et moral brouillant ou effaçant parfois la réflexion scientifique, l'auteur se propose de mener une réflexion dépassionnée axée sur cinq aspects principaux (qui forment les cinq parties, rigoureusement charpentées et abondamment subdivisées, de l'ouvrage), sur un mode chronologico-thématique : l'idéologie SS, le développement de la SS armée (on ne l'appelle pas encore Waffen-SS) entre 1933 et 1939, la formation et l'éducation dans la Waffen-SS, sa structure sociale et enfin, son processus d'expansion pendant les années de guerre. Au terme d'une démonstration d'une grande rigueur scientifique (abondance des références, conclusions partielles, présentation de 32 tableaux, graphiques et organigrammes), l'auteur met en évidence, outre la forte dimension idéologique et supranationale de la Waffen-SS (l'idée de la communauté raciale allait bien au-delà des frontières de l'Allemagne), l'incroyable faisceau de contradictions et de paradoxes que la branche armée de la SS a développé au cours de sa courte histoire; à la fois moderne et archaïque, homogène et hétérogène, traditionnelle et révolutionnaire, fermement 
attachée à ses principes et dotée d'une surprenante capacité d'adaptation, la Waffen-SS ne put au final résoudre ses contradictions, par ailleurs empêtrée dans une lutte d'influence avec la Wehrmacht, à laquelle la Waffen-SS souhaitait peu à peu ôter tout rôle directeur.

3 En son temps, le travail de B.W. a sans aucun doute remis en cause certaines idées reçues de l'époque sur la Waffen-SS (la faible politisation des soldats, leur volonté de remplacer la Wehrmacht comme bras armé du Troisième Reich, etc.). Néanmoins, près de trente ans après la première édition et malgré quelques ajouts actualisant la bibliographie et l'état de la recherche jusqu'en 1996, il s'avère aujourd'hui daté et dépassé. D'autres études ont renouvelé les approches par l'ajout de nouvelles sources (B.W. regrettait de n'avoir pu accéder aux archives de la Waffen-SS conservées dans le bloc de l'Est, à Prague et à Potsdam) et l'analyse de thèmes peu ou pas explorés par B.W., tels que la logique de la violence et de la brutalité ou la contribution militaire de la Waffen-SS au conflit. À ce jour, le livre de B.W. constitue donc bien davantage une référence et un outil de travail sur les structures de la Waffen-SS que le Standardwerk du début du XXIe siècle sur son histoire.

4 Sébastien Bertrand (Lycée Félix-Faure, Beauvais) 